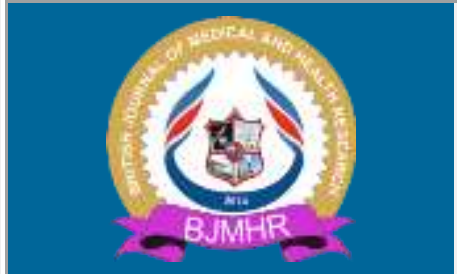

\title{
BJMHR
}

British Journal of Medical and Health Research Journal home page: www.bjmhr.com

\section{New Face of Clinical Teaching and Learning: Social Media in Medical Education Use of WhatsApp among Medical Students in Clinical Teaching at Oman Medical College}

\author{
Firdous Jahan $^{1 *}$, Muhammad A Siddiqui², Dr Zaid A Mukhlif ${ }^{3}$, \\ Khulood Abdullah Al Kalbani ${ }^{1}$, Aya Issa Al Rawahi ${ }^{1}$ \\ 1.Department of Family Medicine, College of Medicine and Health Sciences (former Oman \\ Medical College), National University Science and Technology, Sohar, Oman \\ 2.Department of Research \& Performance, Saskatchewan Health Authority, Regina, SK, \\ Canada \\ 3.Fallujah Health Sector, Ministry of Health, Iraq
}

\section{ABSTRACT}

Medical education has its core values of confidentiality and formal conduct while social media involved sharing and openness, connection which seems to be contradictory for medical professionalism. Main purpose of this study was to explore the students' perception, attitudes and barriers about the professional use of social media and to assess the experiences of undergraduate on the improvement of clinical teaching through the incorporation of social media applications. A cross sectional survey based study was carried out at Oman Medical College. All final year students consented to participate were included in the study. Data was collected on self-administered questionnaire in which core elements were divided demographics, type and frequencies of different social media usage, student's perception about WhatsApp utilization and barriers of not using social media. Statistical analysis was performed using SPSS (IBM SPSS Statistics 20.0). Data were expressed in frequencies, mean and percentages. A total of 76 participants were enrolled in which $5(6.6 \%)$ were male and 71 (93.4\%) were aged between 20-25 years of age. Among all 57 (75\%) were Omani nationals and almost all $(98.7 \%)$ participants used social media of which $35(46.1 \%)$ were android, 29 (38.2\%) IOS, and 12 (15.8\%) were other operating system users. All participants daily spend some time on YouTube, Facebook, Twitter and WhatsApp. In contrast, responses of all participants' indicated that they never make use of Wiki, Chat On and hangout. More than half of the study participants believed that lack of internet access is one the main barrier of nonutilization of social media. Medical students prefer online media for communication and medical information along with usage of WhatsApp in medical education and learning is helpful for improving and enhancing the interactive learning. The students' response emphasizes positive response and experiences of their learning and discussions provided an effective space for integrated small group clinical teaching and learning.

Keywords: Social media, medical education, WhatsApp, clinical teaching, learning 


\section{INTRODUCTION}

Social networking sites or application enables users to communicate with each other and share information, comments, messages, videos and images. Social media use in medical education to support information sharing and collaboration between individuals [1]. This has extended to the health care and medical education giving health information online and share their experiences and knowledge [2]. Medical education and clinical teaching has its values of confidentiality while social media involved sharing and openness with connection [3]. Students on social networking sites more personal, establish connections can be used in learning in medical education [4].

In developing innovation and evolving medical education system, educators should consider utilizing the opportunities provided by social media, such as active learning through personal engagement, facilitation of communication and feedback [5]. The use of WhatsApp provides students with a cost effective way to enhance learning in medical education, collaboration, and access to resources and interaction without physical location restrictions [6].

Potential barriers to using social media for medical education include inadequate knowledge about how to access electronic information, technical issues, lack of educational content in social media and limited time to access social media for learning [7]. To integrate the social media's opportunities and challenges into the current existing frameworks is needed to establish best practices in clinical medical education research [8].

Medical students are using various social media including WhatsApp, which is generally used for communication. WhatsApp creates learning prospects for students to facilitate and augment their knowledge in encouraging learning, interaction and to promote active learning [9]. Students' active participation in WhatsApp group learning provided opportunities for tutor facilitators' feedback and peer learning and peer feedback to learners on their performance [10].

In final year all students rotates in 6 rotations including medicine, surgery, obstetrics and gynecology, psychiatry, pediatrics and family medicine. Goals of family medicine program are to have a competent clinician in respect of diagnosis and providing evidence- based costeffective management of conditions commonly met at the primary health care level. Family medicine rotation at Oman Medical College comprises of clinical teaching at primary health care centers. Students are divided to small group of 4-5 for each health center. Use of WhatsApp is very common among students as a medium of communication. This study aimed to explore the students' perception, attitudes and barriers about the use of Social Media in clinical teaching, enhancing and promoting learning through the incorporation of a social media 
application, WhatsApp, as a mode of communication for enhancing the integration of theory and clinical practice.

\section{MATERIALS AND METHOD}

This is a cross sectional study, conducted at Oman Medical College in relation to the perception, attitudes and barriers about the professional use of Social Media among undergraduate medical students. Final year students group (15-16 students in each group) rotating in family medicine Department every 6 weeks was asked to be a part of this group. One faculty administrator from the department monitored the activity. This activity was carried out 2 days per week (Monday and Wednesday). Questions were given on WhatsApp: short answer, MCQ, pictures with clinical finding, data to analyze. Students in family medicine rotation were given time to respond to the questions asked. The facilitator faculty monitored all the responses and their timing. Correct answers were given next day and a brief session was conducted twice a week with student's verbal reflection. The study population was engaged in a WhatsApp discussion group to enhance their integration of theory and clinical practice. Students who agreed to participate were inducted in the WhatsApp group. The proposal was approved by College Research and Ethical Committee to conduct the research.

Data collected from a purposive sample of undergraduate final year medical students using a self-filled questionnaire at the end of family medicine rotation. A favorable ethical opinion was obtained from institutional ethics board and an informed consent was obtained from study participants. Survey instrument made after literature search and reviewed and agreed after several brain storming sessions with family medicine faculty facilitator and experts. Validity of the questionnaire was done in different dimension including apparent, face, content and construct which reflects the concepts to be measured. Validation of questionnaire on small group (pilot) was also performed. All participants after explaining the importance and objective of the study and taking informed consent, participants were requested to respond anonymously to written questions.

Survey questionnaire comprised of four components. The first part of the questionnaire consists of demographics. This included the questions regarding the age, gender, nationality, social media and type of mobile operating system usage. The second part of the questionnaire consists of information relating to type and frequencies of different social media usage. Third part was regarding student's perception about WhatsApp utilization in case studies in family medicine rotation and the fourth part was comprised of set of questions regarding barriers not using Social Media. Data was analyzed using Statistical Package for Social Sciences (SPSS) version 24 for percentage, frequency and mean. Data was expressed in frequencies and percentages for questionnaire responses. T-test was used to compare differences between groups. 


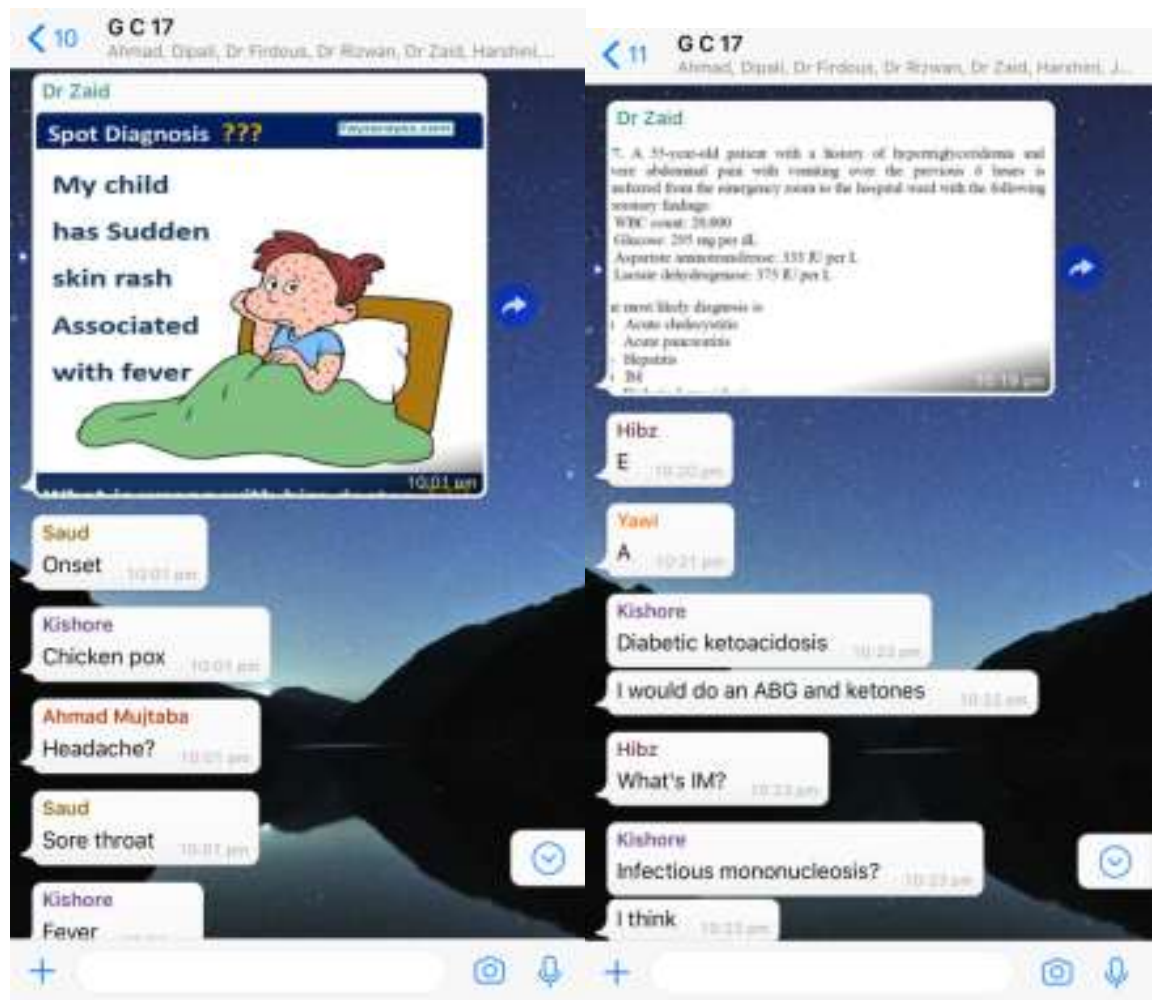

\section{RESULTS AND DISCUSSION}

A total of 76 participants were enrolled over one year in 6 rotations in which $5(6.6 \%)$ were male and 71 (93.4\%) were female. Majority of the participants, 71 (93.4\%) were aged between 20-25 years of age, $2(2.6 \%)$ were aged less than 20 years and $3(3.9 \%)$ was age above 25 years. Among all 57 (75\%) were Omani nationals and 19 (25\%) were foreign students. Almost all (98.7\%) participants used social media of which 35 (46.1\%) were android, 29 (38.2\%) IOS, and $12(15.8 \%)$ were other operating system users. More than two third of the participants (75\%) using social media for more than 5 years and $14(18.4 \%) 3$ to 5 years and $5(6.6 \%)$ were using less than a year. Participants were asked about frequencies of different media usage, their responses were in never, occasionally, once a month, once a week and daily (Table 1). All participants daily spend some time on YouTube, Facebook, Twitter and WhatsApp. In contrast, responses of all participants' indicated that they never make use of Wiki, Chat On and hangout.

Table 1. Usage of Social Media to learn Medicine used among Medical student

\begin{tabular}{llllll}
\hline & Never & Occasionally & Once a month & Once a week & Daily \\
\hline YouTube & 0 & 0 & 0 & 0 & $76(100)$ \\
Wiki & $76(100)$ & 0 & 0 & 0 & 0 \\
Facebook & 0 & 0 & 0 & 0 & $76(100)$ \\
Twitter & 0 & 0 & 0 & 0 & $76(100)$ \\
WhatsApp & 0 & 0 & 0 & 0 & $76(100)$ \\
ChatOn & $76(100)$ & 0 & 0 & 0 & 0 \\
Hangout & $76(100)$ & 0 & 0 & 0 & 0 \\
Drop Box & $46(60.5)$ & $14(18.4)$ & $9(11.8)$ & $4(5.3)$ & $3(3.9)$ \\
Messenger & $53(69.7)$ & $10(13.2)$ & $3(3.9)$ & $4(5.3)$ & $6(7.9)$ \\
We chat & $69(90.8)$ & $4(5.3)$ & $2(2.6)$ & 0 & $1(1.3)$ \\
\hline
\end{tabular}




\begin{tabular}{llllll}
\hline Flip Board & $69(90.8)$ & $4(5.3)$ & $2(2.6)$ & $1(1.3)$ & 0 \\
LinkedIn & $58(76.3)$ & $13(17.1)$ & $4(5.3)$ & $1(1.3)$ & 0 \\
Research Gate & $65(85.5)$ & $6(7.9)$ & $3(3.9)$ & $1(1.3)$ & $1(1.3)$ \\
Blog & $65(85.5)$ & $6(7.9)$ & $4(5.3)$ & 0 & 0 \\
Skype & $59(77.6)$ & $14(18.4)$ & $1(1.3)$ & $1(1.3)$ & $1(1.3)$ \\
Talk ray & $70(92.1)$ & $3(3.9)$ & $1(1.3)$ & $2(2.6)$ & 0 \\
Viber & $50(65.8)$ & $20(26.3)$ & $4(5.3)$ & $1(1.3)$ & $1(1.3)$ \\
Google+ & $23(30.3)$ & $11(14.5)$ & $4(5.3)$ & $6(7.9)$ & $32(42.1)$ \\
Podcasts & $61(80.3)$ & $9(11.8)$ & 0 & $5(6.6)$ & $1(1.3)$ \\
Instagram & $14(18.4)$ & $6(7.9)$ & $2(2.6)$ & $2(2.6)$ & $52(68.4)$ \\
Yahoo & $47(61.8)$ & $19(25)$ & $5(6.6)$ & $3(3.9)$ & $2(2.6)$ \\
Web MD & $28(36.8)$ & $14(18.4)$ & $8(10.5)$ & $14(18.4)$ & $12(15.8)$ \\
Myspace & $66(86.6)$ & $5(6.6)$ & $3(3.9)$ & $2(2.6)$ & 0 \\
Netlog & $72(94.7)$ & $1(1.3)$ & $2(2.6)$ & $1(1.3)$ & 0 \\
Vine & $68(89.5)$ & $3(3.9)$ & $3(3.9)$ & $1(1.3)$ & $1(1.3)$ \\
BBM & $62(81.6)$ & $6(7.9)$ & $4(5.3)$ & $1(1.3)$ & $3(3.9)$ \\
Reddit & $71(93.4)$ & $1(1.3)$ & $2(2.6)$ & $2(2.6)$ & 0 \\
Tumbir & $68(89.5)$ & $3(3.9)$ & $1(1.3)$ & $3(3.9)$ & $1(1.3)$ \\
Pintrest & $56(73.7)$ & $7(9.2)$ & $2(2.6)$ & $5(6.6)$ & $6(7.9)$ \\
Other & $55(72.4)$ & $5(6.6)$ & $3(3.9)$ & $2(2.6)$ & $11(14.5)$ \\
\hline
\end{tabular}

Study participants were inquired about their perception regarding WhatsApp application (table 2). More than two third of study participants (91.8\%) had positive experiences using the WhatsApp group, find ethical way to engage friends and family/increase socialization $(86.8 \%)$ and believe it enhanced medical education (78.9\%) and improve their clinical knowledge and skills $(76.3 \%)$.

Table 2: Use of WhatsApp in Clinical teaching: Impact/Perception of Students

\begin{tabular}{|c|c|c|c|c|c|}
\hline & $\begin{array}{l}\text { Strongly } \\
\text { agree }\end{array}$ & Agree & Neutral & Disagree & $\begin{array}{l}\text { Strongly } \\
\text { Disagree }\end{array}$ \\
\hline $\begin{array}{l}\text { Positive experiences using the } \\
\text { WhatsApp group }\end{array}$ & $36(47.4)$ & $33(43.4)$ & $6(7.9)$ & 0 & $1(1.3)$ \\
\hline $\begin{array}{l}\text { Ethical way to engage friends and } \\
\text { family/ increase socialization }\end{array}$ & $39(51.3)$ & $27(35.5)$ & $10(13.2)$ & 0 & 0 \\
\hline Opportunity for clarification & $32(42.1)$ & $32(42.1)$ & $9(11.8)$ & $3(3.9)$ & 0 \\
\hline $\begin{array}{l}\text { An appropriate resource for } \\
\text { academic information }\end{array}$ & $24(31.6)$ & $32(42.1)$ & $14(18.4)$ & $5(6.6)$ & $1(1.3)$ \\
\hline $\begin{array}{l}\text { An appropriate resource for } \\
\text { health information }\end{array}$ & $20(26.3)$ & $30(39.5)$ & $21(27.6)$ & $3(3.9)$ & $2(2.6)$ \\
\hline It enhanced medical education & $26(34.2)$ & $34(44.7)$ & $15(19.7)$ & $1(1.3)$ & 0 \\
\hline Enhanced professional learning & $23(30.3)$ & 25 (32.9) & $22(28.9)$ & $5(6.6)$ & $1(1.3)$ \\
\hline $\begin{array}{l}\text { Positive impact on clinical } \\
\text { teaching }\end{array}$ & $20(26.3)$ & $28(36.8)$ & $23(30.3)$ & $4(5.3)$ & $1(1.3)$ \\
\hline $\begin{array}{l}\text { It increased my knowledge and } \\
\text { clinical skill }\end{array}$ & $22(28.9)$ & $36(47.4)$ & $16(21.1)$ & $1(1.3)$ & $1(1.3)$ \\
\hline $\begin{array}{l}\text { Interesting cases seen and } \\
\text { discussed }\end{array}$ & $19(25)$ & $27(35.5)$ & $27(35.5)$ & $3(3.9)$ & 0 \\
\hline $\begin{array}{l}\text { Integrating theory and clinical } \\
\text { practice }\end{array}$ & $26(34.2)$ & $22(28.9)$ & $13(17.1)$ & $9(11.8)$ & $6(7.9)$ \\
\hline
\end{tabular}


Figure 1 shows the answers of participants regarding barriers related to Social Media. More than half of the study participants believed that lack of internet access is one the main barrier of non-utilization of social media. A quarter of study participants believe that people become

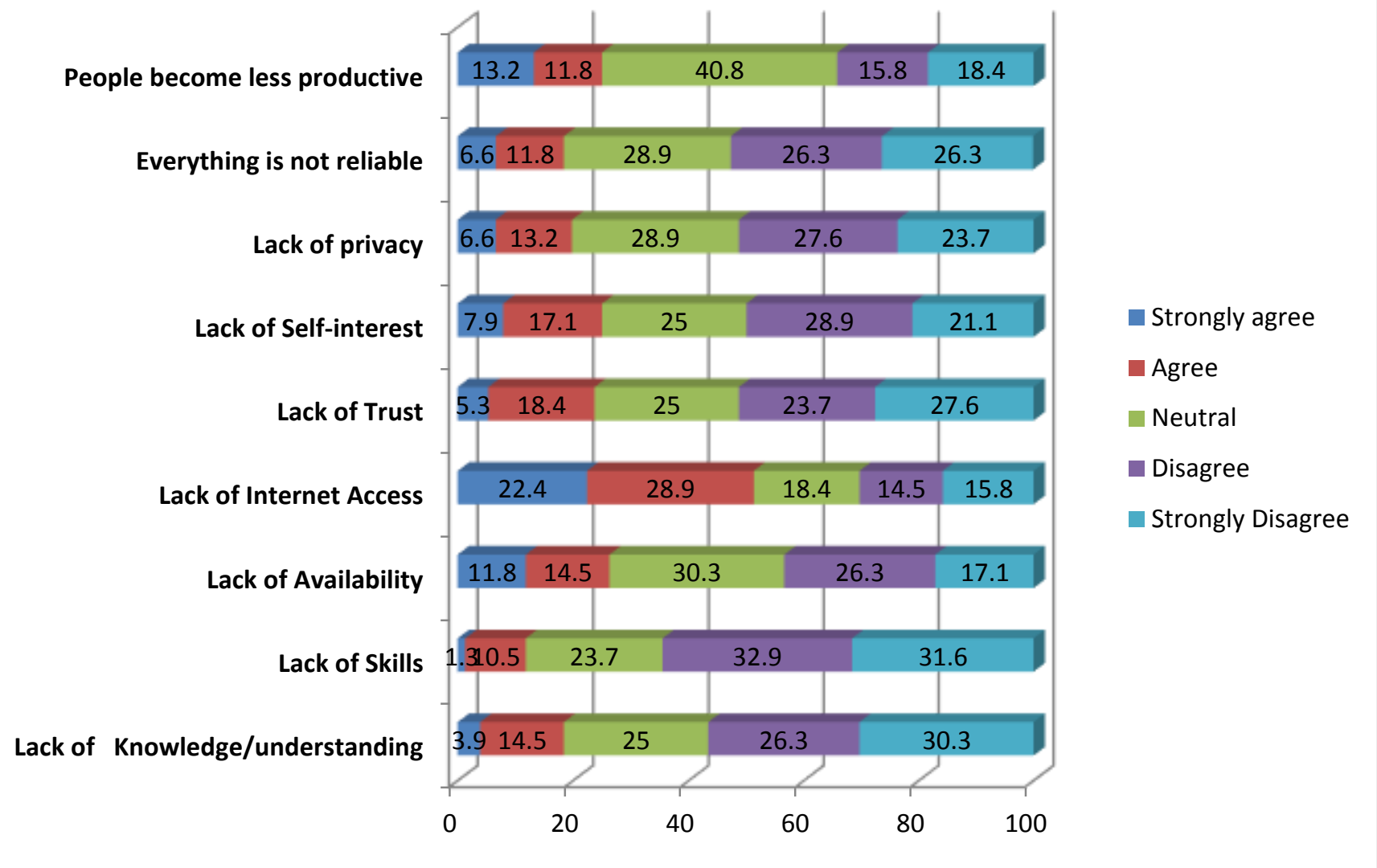

less productive using social media.

Figure 1. Barriers not using Social Media for Medical Education

\section{DISCUSSION}

The use of WhatsApp social communication is popular among students community and its successful integration into clinical teaching is a well-established phenomenon [11]. The record of communication also allows for tutors to reflect back on student participation rates and the effectiveness of facilitating discussions [12]. In our study all students are using social media in one or other way. Daily spend on social media was commonly involved You Tube, WhatsApp, Face Book and Twitter[Table 1).

More than two third of study participants had positive experiences using the WhatsApp group, find ethical way to engage friends and family/increase socialization. This is an adequate solution for communication as reported in the literature [13]. Our medical students in this study believe that it enhanced medical education and improve their clinical knowledge and skills. Same results are shown in other studies that the usage of social media in education and learning is helpful for the purpose of enhancing the interactive learning [14-15]. Students reflected a positive learning experience in the WhatsApp discussion group and with access to their 
educators and peers when they needed guidance or information. Positive learning experiences included access to a variety of clinical cases and information, the creation of a learning platform and the availability of educators and peers to answer questions. Literature also reports that WhatsApp usage showed no relationship with the academic performance among Saudi medical students [16].

Students in this study experienced that their WhatsApp discussion group helped them critical thinking and how to apply theory in clinical teaching. Participants appreciated the presence of their facilitator in the group who monitored their activity in the group with guidance in decision making, when required [Table2]. Other studies has shown that this can be a useful tool for students in the PBL process through promoting of media sharing, improving communication, generating learning opportunities and providing a record of discussions [17-18].

In this study of participants have also given barriers related to Social Media. More than half of the study participants believed that lack of internet access is one the main barrier of nonutilization of social media [Fig I]. A quarter of study participants believe that people become less productive using social media. Medical students should appreciate the benefit as well disadvantages of social media to get maximum desired outcome [18-19].

Medical students are future doctors' needs adequate clinical teaching in a limited time frame. In experiential reflection participants of our study shared that their WhatsApp interaction helped them in the application of knowledge during clinical practice. Students shared that discussion groups were interactive with positive learning experience. There was easy access to their educators and peers when they needed supervision. Literatures have shown the same result that the usage of social media in education and learning is helpful for the purpose of enhancing the interactive learning [20-21]. WhatsApp is a cost effective social media can be used to improve the interaction between students and facilitators for motivation and learning [22]. Moreover mock assessment and formative assessment feedback as well as get advantage of peer assisted learning (PAL).

\section{CONCLUSION}

The findings of this study facilitates a method by which communication and clinical education within medical student groups can improve learning and indicate the utility, feasibility and acceptability of WhatsApp. The use of WhatsApp provides students with a support contribution towards the usage of social media applications in teaching and learning structure to enhance the integration of their theory and clinical practice. The reflections of students highlight their positive experiences of the enhancement of their learning as a result of the intervention. The intervention provides a space for collaborative clinical teaching and learning, sharing information, and to enhance the teaching and learning process. 


\section{REFERENCES}

1. George DR, Dellasega C. Social media in medical education: two innovative pilot studies. Med Educ. 2011;45(11):1158-9.

2. Giordano C, Giordano C. Health professions students' use of social media. J Allied Health $2011 ; 40(2) 78-81$.

3. Essary AC. The impact of social media and technology on professionalism in medical education. J Physician Assist Educ. 2011;22(4):50-3.

4. Hommes J, Rienties B, de Grave W. Visualizing the invisible: a network approach to reveal the informal social side of student learning. Adv Health Sci Ed. 2012;17(5):743757.

5. Black EW, Thompson LA, Duff WP, Dawson K, Saliba H, Black NM. Revisiting social network utilization by physicians-in-training. J Grad Med Educ. 2010;2(2):289-93.

6. Cook D.A., Levinson A.J., Garside S., Dupras D.M., Erwin P.J., Montori V.M. Internetbased learning in the health professions: a meta-analysis. JAMA. 2008;300(10):11811196.

7. Amy T. Wang,a Nicole P. Sandhu,a Christopher M. Wittich,a Jayawant N. Mandrekar,b and Thomas J. Beckmana. Using Social Media to Improve Continuing Medical Education: A Survey of Course Participants. Mayo Clin Proc. 2012; 87(12): 11621170.

8. Saarinen C, Arora V, Fergusen B, Chretien K. Incorporating social media into medical education. Academic Internal Medicine Insight. 2011;9(1):12-13, 19.

9. Cartledge P, Miller M, Phillips B. The use of social-networking sites in medical education Med Teach. 2013; 35(10):847-57. doi: 10.3109/0142159X.2013.804909..

10. Yeboah J, Ewur G.D. The impact of WhatsApp messenger usage on students' performance in Tertiary Institutions in Ghana', Journal of Education and Practice 2014; 5(6), 157-164.

11. Thompson L.A., Dawson K., Ferdig R. The intersection of online social networking with medical professionalism. J Gen Intern Med. 2008;23(7):954-957

12. Cochrane, T.D. Critical success factors for transforming pedagogy with Mobile Web 2.0', British Journal of Education Technology 2014; 45(1), 65-82. http://dx.doi. org/10.1111/j.1467-8535.2012.01384.x

13. Hossain IT, Mughal U, Atalla B, Franka M, Siddiqui S, Muntasir M. Instant messaging - one solution to doctor-student communication? Med Educ Online. 2015;20:30593.

14. Zulfikar I, Zaheer F, Baloch Q, Ahmed F. The new face of learning: Social media innovating medical education. Int J Educ Psychol Res 2018; 4:1-5. 
15. Willemse, J.J., 2015, 'Undergraduate nurses reflections on Whatsapp use in improving primary health care education', Curationis 38(2), Art. \#1512, 7 pages. http://dx.doi.org/10.4102/curationis.v38i2.1512

16. Alkhalaf AM, Tekian A, Park YS. The impact of WhatsApp use on academic achievement among Saudi medical students, Med Teach. 2018, 17:1-5. doi: 10.1080/0142159X.2018.1464652

17. Raiman L, Antbring R, Mahmood A. WhatsApp messenger as a tool to supplement medical education for medical students on clinical attachment. BMC Medical Education 2017; 17:7.

18. Handelman G. We should embrace WhatsApp and try to mitigate concerns BMJ 2018; 360 doi: https://doi.org/10.1136/bmj.k1311 .

19. Morton CE, Saleh SN, Smith SF, Hemani A, Ameen A, Bennie TD, et al. Blended learning: how can we optimise undergraduate student engagement? BMC Med Educ. 2016;16:195.

20. Amry AB. The impact of whatsapp mobile social learning on the achievement and attitudes of female students compared with face to face learning in the classroom European scientific journal. 2014; 10-22.

21. Zulfikar I, Zaheer F, Baloch Q, Ahmed F. The new face of learning: Social media innovating medical education. Int J Educ Psychol Res 2018;4:1-5.

22. Tulika B, Dhanajay J. A study of student's experience of WhatsApp mobile learning. Global Journal of Human-social Science Research. 2014; 14: (4).

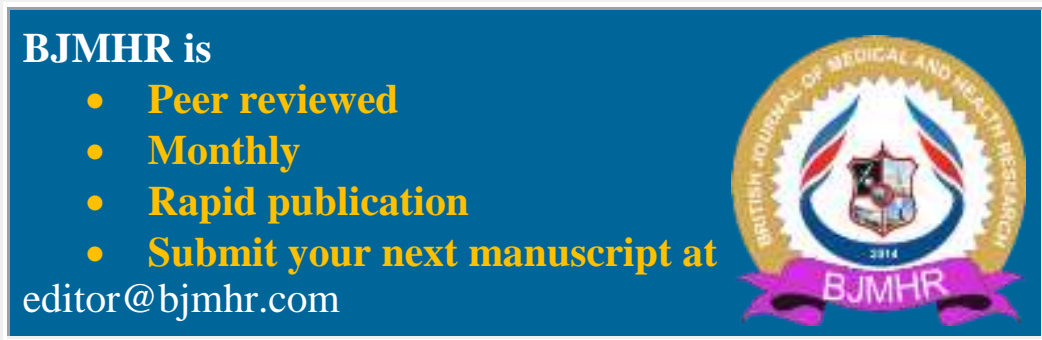

